\title{
Smart Learning Platform for Management Executive: A Systematic Literature Review
}

\author{
Umar Al Faruqi \\ School of Electrical Engineering and Informatics \\ Institut Teknologi Bandung \\ Bandung, Indonesia \\ alfaruqi@students.itb.ac.id
}

\begin{abstract}
Development of digital transformation towards the information age have made significant change in various sectors and industries, including education. This transformation also needs to consider social problem solving with human centered design approach. One of the learning methods enabled by the technology development of this transformation is smart learning, that aims to improve the quality of learning utilizing intelligent technology in accordance with the learning context. This paper explains systematic literature review conducted as initial study in the research of smart learning for executives. The journals used in this review are various international journals obtained from some reputable journal databases. After going through the filtering process using several inclusion and exclusion criteria, 15 journals were analyzed based on the research questions. From the review, it can be concluded that smart learning can improve the learning process in terms of motivation, engagement, and learning performance. Various information technology is used to enhance the efficiency and effectiveness of smart learning, which provides the learning needs for executive education.
\end{abstract}

Keywords-smart learning, executive, learning method, technology, literature review

\section{INTRODUCTION}

With the rapid development of technology, digital transformation goes towards a change to the next era, the information age. This change is marked by the development of information technology which is often referred to as Industrial Revolution 4.0. Community systems that utilize the development of this transformation also need to consider aspects of humanity so that a technological concept appears that can solve social problems with a human centered design approach.

The need for competent and adequate human resources is also felt by business people. This triggers the use of technology to improve the quality of products or services offered. By utilizing data and information, supported by related technology, companies are slowly starting to change conventional business processes into digital business processes. This change also happens in education sector as well. To accommodate this need, we need a platform that can provide training and learning for company executives so that they have the competence to carry out digital transformation on their companies. To solve this problem, we need a new approach of learning, which is smart learning.

So far, there is no clear and definite definition of smart learning. The definition that can be used is a learning that can be done anywhere and still fits the learning context [1]. This learning adjusts to students as users, taking into account the competencies to be achieved with the ability of students, including learning progress, learning styles, and learning method preferences.

The concept of smart learning is an effective and efficient learning method by utilizing smart technology in relevant systems. The main core of learning is the students themselves so that smart learning can provide service-based self learning. An ideology of smart education in a framework is part of three main elements: smart environment, smart pedagogy, and smart learner as the center $[2]$. 
Based on this definition, in this study, smart learning is defined as a learning method that aims to improve the quality of learning utilizing intelligent technology in accordance with the learning context.

Smart learners need to have various aspects of competence, which are grouped into four categories: knowledge, skills, behavior, and values. The smart pedagogy architecture itself consists of four stages that support smart learning, starting from basic knowledge and skills, comprehensive understanding skills, personal expertise, and collective intelligence. This is supported by a smart learning environment based on technology by utilizing digital resources so learning can be done anytime and anywhere. The empowerment of smart learning needs to be supported by the use of relevant hardware and software [2].

There are three important domains in smart learning, namely epistemology, psychology, and technology. Epistemologically, this learning concept changes the previous method by presenting the formation of a new mental model for students through different learning experiences. Smart learning also needs to utilize adequate information technology in order to provide personalized learning so that learning methods become smarter [3].

The challenge faced in implementing the SLE (Smart Learning Environment) reference model is its compatibility with the current conditions for each technology that is to be used. The need for this approach to be accepted as an appropriate method is the placement of new methods in an existing system, as well as an appropriate framew ork that can support new methods but also ensure effectiveness on the system. Some technologies that are still being considered are AR (Augmented Reality) and VR (Virtual Reality), digital badges, and blockchain [4].

This study aims to understand smart learning methods that can change learning behavior so as to improve the quality of the learning process, platform that uses a smart learning approach utilizing relevant service-based information technology, and appropriate educational methods in smart learning so that learning achievement is optimal. The output of this research is a smart learning framework for executive education that can be implemented in various learning platform utilizing information technology.

\section{RESEARCH Methodology}

In this research, the methodology used is systematic literature review. Using this method, research problems are answered by understanding some preceding journals whose topics are related to smart learning for executives.

\section{A. Systematic Literature Review}

Systematic literature review (SLR) identifies, selects and critically evaluates research to answer clearly formulated questions. Systematic reviews must follow clear plans where criteria are clearly stated before the review is carried out. The SLR is a comprehensive and transparent search carried out on many databases and literature that can be replicated and reproduced by other researchers. This involves planning a well thought out search strategy that has a specific focus in orde $r$ to answers to defined questions. This review identifies the type of information within a known time frame. Search terms, search strategies (including database names, platforms, search dates) and restrictions must all be included in the review.

In the process of SLR, searches are performed on the journal databases, which are IEEE Xplore, Science Direct, Springer, ACM Digital Library, and Scopus. The search process utilizes AND and OR operators so that the results obtained are in accordance with the research question. The use of operator AND serves as a limitation of the search process to contain all keywords, while the use of the OR operator is used to expand the scope of the search to include at least one of the keywords. 
After obtaining various journals from the database, journal selection is performed using certain filters. These filters are inclusions and exclusions to limit the journals used in the SLR so that the literature used are only journals that are relevant to the research purpose. In addition, journal ranking is also considered to ensure that there are at least a number of internationally recognized journals to be used as reference journals in this research. Finally, the SLR will sum up conclusions from the study of literature related to the formulation of questions regarding smart learning.

\section{B. Research Questions}

Research questions aim to limit the scope of research to make it easier for researchers to focus on the specific research. Research questions and motivations for this study are stated in the table below.

Table 1 Research Questions and Motivations

\begin{tabular}{|l|l|l|}
\hline \multicolumn{1}{|c|}{ ID } & \multicolumn{1}{|c|}{ Research Questions } & \multicolumn{1}{c|}{ Motivations } \\
\hline RQ1 & $\begin{array}{l}\text { How is the smart learning method } \\
\text { that can improve learning } \\
\text { motivation, competencies, and } \\
\text { learning skills? }\end{array}$ & $\begin{array}{l}\text { Understand smart learning methods } \\
\text { that can improve learning } \\
\text { motivation, competencies, and } \\
\text { learning skills }\end{array}$ \\
\hline RQ2 & $\begin{array}{l}\text { What service-based information } \\
\text { technology which can be used to } \\
\text { improve the quality of learning in } \\
\text { smart learning platform? }\end{array}$ & $\begin{array}{l}\text { Understand service-based } \\
\text { information technology that is } \\
\text { effective in improving the quality } \\
\text { of learning }\end{array}$ \\
\hline RQ3 & $\begin{array}{l}\text { How does a smart learning } \\
\text { platform can provide the learning } \\
\text { needs by using a particular } \\
\text { educational approach? }\end{array}$ & $\begin{array}{l}\text { Understand how smart learning } \\
\text { platform learning can provide the } \\
\text { learning needs by using an } \\
\text { educational method approach }\end{array}$ \\
\hline
\end{tabular}

\section{Searching Process}

The searching process of SLR is performed on several databases. The database used in this search process is as follows.

Table 2 Journal Databases

\begin{tabular}{|l|l|l|}
\hline ID & \multicolumn{1}{|c|}{ Journal Database } & \multicolumn{1}{c|}{ Database Link } \\
\hline S1 & IEEE Xplore & https://ieeexplore.ieee.org \\
\hline S2 & Science Direct & https://www.sciencedirect.com \\
\hline S3 & SpringerLink & https://link.springer.com \\
\hline S4 & ACM Digital Library & https://dl.acm.org \\
\hline S5 & Scopus & https://www.scopus.com \\
\hline
\end{tabular}

In conducting the search, an initial process is carried out using a number of keywords that help limit the search process. The keywords used are as follows.

- Smart learning

- Executive education

- E-learning OR Electronic learning

- Smart learning environment 
- Collaborative learning

- Blended learning

For the SLR process, by utilizing a number of these keywords, better search keywords are formulated to fit the scope of this research. The searching process used these three keywords in all of the journal databases.

Table 3 List of Keywords Used

\begin{tabular}{|l|l|}
\hline \multicolumn{1}{|c|}{ ID } & \multicolumn{1}{c|}{ Keywords } \\
\hline KW1 & "Smart learning" AND executive \\
\hline KW2 & (E-learning OR "Electronic learning") AND "executive education" \\
\hline KW3 & "Smart learning environment" \\
\hline
\end{tabular}

\section{Result Finding}

The search process carried out retrieved many journal documents from various databases. The total number of journals obtained from all databases is 1286 journals. The distribution of the journals based on the database is shown in the following table.

Table 4 Initial Journals Retrieved from Databases

\begin{tabular}{|c|l|c|}
\hline No & Search Database & Results \\
\hline 1 & IEEE Xplore & 31 \\
\hline 2 & Science Direct & 443 \\
\hline 3 & Springer Link & 618 \\
\hline 4 & ACM Digital Library & 9 \\
\hline 5 & Scopus & 185 \\
\hline \multicolumn{2}{|c|}{ Total } & $\mathbf{1 2 8 6}$ \\
\hline
\end{tabular}

In this study, some inclusions and exclusions were made to limit the journals to be used. By using these criteria, the search process will go through several filters until only relevant journals are utilized in the review.

Table 5 Inclusion and Exclusion Criteria

\begin{tabular}{|l|l|l|}
\hline \multicolumn{2}{|l|}{ Criteria } \\
\hline \multirow{4}{*}{ Inclusion } & I1 & Full text articles \\
\cline { 2 - 3 } & I2 & Written in English \\
\cline { 2 - 3 } & I3 & Research articles in journals, magazines, and proceeding \\
\cline { 2 - 3 } & I4 & Related to smart learning for executives \\
\hline Exclusion & E1 & Research articles in a book, book chapters \\
\cline { 2 - 3 } & E2 & Older than 4 years (before 2016) \\
\cline { 2 - 3 } & E3 & Research articles that is not related to learning in an abstract \\
\cline { 2 - 3 } & E4 & Duplicate articles from different database \\
\hline
\end{tabular}

For each step, filtering used some inclusion and exclusion criteria. After filtering using the criteria, few journals were obtained for the review. The results of the journal filtering are displayed in following tables. The steps show the number of journals for each keyword and each database. 
Table 6 Step 1 Filtering

\begin{tabular}{|c|c|c|c|c|c|c|}
\hline \multicolumn{7}{|c|}{ Step 1 - Initial Process } \\
\hline Source & S1 & S2 & S3 & S4 & S5 & Total \\
\hline KW 1 & 0 & 11 & 82 & 0 & 1 & $\mathbf{9 4}$ \\
\hline KW2 & 1 & 401 & 129 & 2 & 5 & $\mathbf{5 3 8}$ \\
\hline KW 3 & 30 & 31 & 407 & 7 & 179 & $\mathbf{6 5 4}$ \\
\hline Total & 31 & 443 & 618 & 9 & 185 & $\mathbf{1 2 8 6}$ \\
\hline
\end{tabular}

Table 7 Step 2 Filtering

\begin{tabular}{|c|c|c|c|c|c|c|}
\hline \multicolumn{7}{|c|}{ Step 2 - I1, I2, I3, E1, E2 } \\
\hline Source & S1 & S2 & S3 & S4 & S5 & Total \\
\hline KW 1 & 0 & 2 & 17 & 0 & 0 & $\mathbf{1 9}$ \\
\hline KW2 & 1 & 5 & 6 & 0 & 0 & $\mathbf{1 2}$ \\
\hline KW 3 & 30 & 15 & 82 & 0 & 16 & $\mathbf{1 4 3}$ \\
\hline Total & 31 & 22 & 105 & 0 & 16 & $\mathbf{1 7 4}$ \\
\hline
\end{tabular}

Table 8 Step 3 Filtering

\begin{tabular}{|c|c|c|c|c|c|c|}
\hline \multicolumn{7}{|c|}{ Step 3 - I4, E3 } \\
\hline Source & S1 & S2 & S3 & S4 & S5 & Total \\
\hline KW1 & 0 & 2 & 2 & 0 & 0 & $\mathbf{4}$ \\
\hline KW2 & 1 & 0 & 1 & 0 & 0 & $\mathbf{2}$ \\
\hline KW3 & 0 & 3 & 6 & 0 & 1 & $\mathbf{1 0}$ \\
\hline Total & 1 & 5 & 9 & 0 & 1 & $\mathbf{1 6}$ \\
\hline
\end{tabular}

The process of retrieving and filtering the journals is illustrated in diagram below.

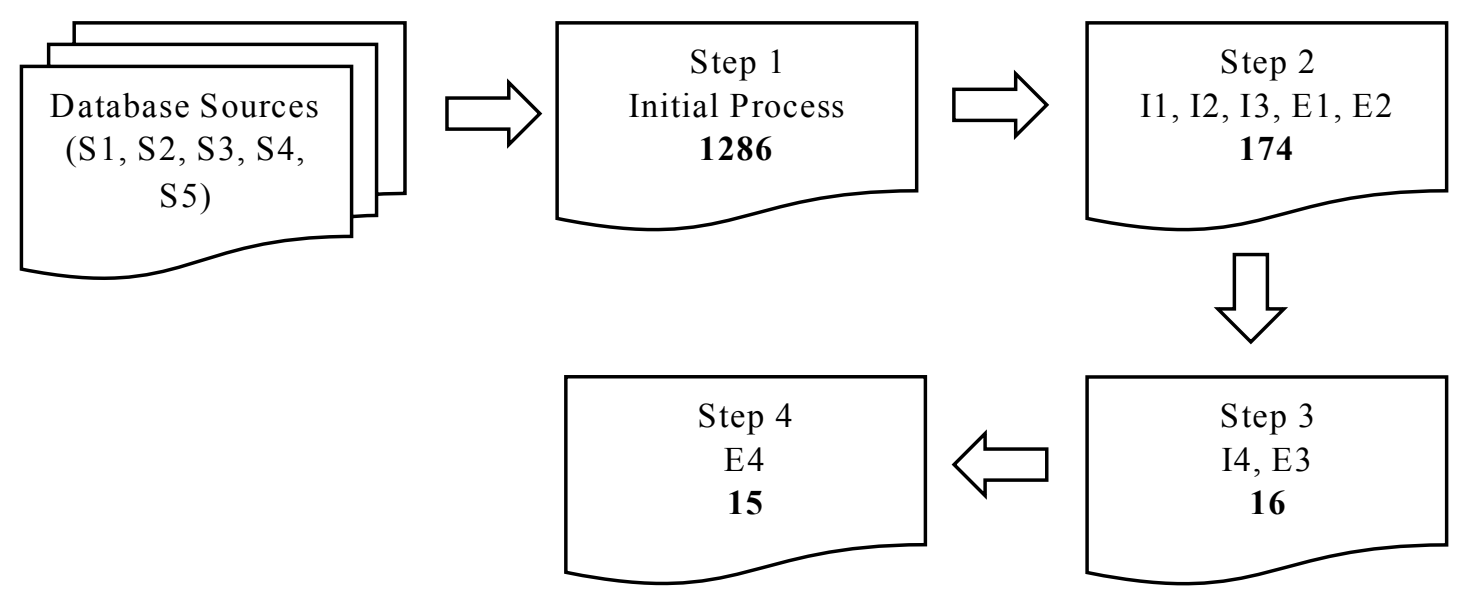

Fig. 1 Journal Filtering Process

After the filtering process with certain inclusion and exclusion criteria, there are 15 journals to be reviewed. Each of these journals is read and analyzed in order to answer the research questions that have been defined. 
III. RESEARCH RESULT

\section{A. Smart Learning Methods for Improving Learning Qualities}

Table 9 Smart Learning Methods for Improving Learning Needs

\begin{tabular}{|c|l|l|}
\hline No & Smart Learning Methods & \multicolumn{1}{|c|}{ Related Article } \\
\hline 1 & Hybrid learning & {$[5][6][7]$} \\
\hline 2 & Learning interfaces & {$[8][9]$} \\
\hline 3 & Collaborative learning & {$[7][10]$} \\
\hline 4 & Smart learning environment & {$[11][12][13][14][15]$} \\
\hline
\end{tabular}

In improving the quality of learning in smart learning, it takes a combination of various methods, such as online and offline, so that the hybrid learning approach can deliver good results in learning. SLE (Smart Learning Environment) is physical environments that are improved to promote better and faster learning by enriching the environment with context-aware and adaptive digital devices [5].

Based on [6], blended learning can increase the effectiveness of learning in terms of awareness, adoption, and outcomes. The use of this method will increase teaching effectiveness and learning effectiveness hence will improve the quality of learning as well. Hybrid learning requires high flexibility from students, teachers, education staff, and systems. Therefore, FTL (Flexible thinking in learning) is needed to enable collaborative learning [7].

In applying SLE to form perceived learning, there are three relevant indicators, whic $h$ are ease of use, social support, and relatedness [15].

\section{B. Information Technology of Smart Learning}

Table 10 Information Technology Used in Smart Learning Platforms

\begin{tabular}{|c|l|l|}
\hline No & \multicolumn{1}{|c|}{ Information Technology } & \multicolumn{1}{|c|}{ Related Article } \\
\hline 1 & Virtual environment & {$[5][6][14][15]$} \\
\hline 2 & Data analytics & {$[11][16][17]$} \\
\hline 3 & Video technology & {$[6][17]$} \\
\hline 4 & Learning management system & {$[11][12][13]$} \\
\hline
\end{tabular}

The use of virtual environments is very supportive for smart learning because it can utilize technological developments which are used as digital environments for learning [14].

In addition, the use of data analytics is also very necessary to support the appropriate technology for smart learning [11]. By utilizing big data analytics, smart learning can provide personalization in learning thus the content of learning is corresponding to students' needs.

The use of video technology has also become very relevant and widely used so students no longer need to be present in the classroom but can access interactive learning material from outside the classroom [6]. This feature will enable various education learning methodology, such as flipped classroom and student-centered learning.

However, the use of this technology must be supported by good LMS (learning management system). The four main components needed by LMS are instructional design models, learning theory, learning interactions, and learning technology qualities [13]. 


\section{Provision of Smart Learning Platform for Learning Needs}

Table 11 Provision of Smart Learning Platform for Learning Needs

\begin{tabular}{|c|l|l|}
\hline No & Smart Learning Provision & Related Article \\
\hline 1 & Motivation & {$[5][16][18]$} \\
\hline 2 & Assessment & {$[16]$} \\
\hline 3 & Effectiveness & {$[6][15][19]$} \\
\hline 4 & Resourceful & {$[10][19]$} \\
\hline
\end{tabular}

Based on [16], the use of smart learning platforms can increase motivation and engagement in learning. This relates to two main principles, which are participation and feedback from learners. The increased motivation can be achieved by implementing the concept of smart learning which can be abbreviated as SMART as well. These concepts are self-directed, motivated, adaptive, resource enriched, and embedded technology [18].

Based on research in [19], the use of e-learning can also improve learning effectiveness by building efficient e-learning infrastructure to facilitate access to various learning resources. In addition, this also needs to be supported by standardization of e-learning systems to enhance the quality of e-learning resources.

\section{CONCLUSION}

In this paper, Systematic Literature Review for Smart Learning Platform has been carried out. The results of SLR have answered several research questions mentioned earlier. Various smart learning methods that can improve the quality of learning are hybrid learning or blended learning, learning interfaces, collaborative learning, and smart learning environments. The use of information technology in smart learning revolves around virtual environments, data analytics, video technology, and learning management systems. Meanwhile, the benefits of smart learning for learning are increased motivation, assessment, effectiveness, and resourceful le arning.

\section{ACKNOWLEDGEMENT}

This research is supported by Smart City and Community Innovation Center which provided executive smart learning platform, namely Eduplatform. This research is conducted in the Department of Electrical Engineering, School of Electrical Engineering and Informatics, Institut Teknologi Bandung.

\section{REFERENCESS}

[1] G.-J. Hwang, "Definition, framework and research issues of smart learning environments," Smart Learning Environments, vol. 1, no. 4, 2014.

[2] Z.-T. Zhu, M.-H. Yu and P. Riezebos, "A research framework of smart education," Smart Learning Environments, vol. 3, no. 4, 2016.

[3] J. M. Spector, "Conceptualizing the emerging field of smart learning environments," Smart Learning Environments, vol. 1, no. 2, 2014. 
[4] T. Hoel and J. Mason, "Standards for smart education - towards a development framew ork," Smart Learning Environments, vol. 5, no. 3, 2018.

[5] S. Freigang, L. Schlenker and T. Köhler, "A conceptual framework for designing smart learning environments," Smart Learning Environments, vol. 5, no. 27, 2018.

[6] e. a. Bokolo Anthony Jr, "Exploring the role of blended learning for teaching and learning effectiveness in institutions of higher learning: An empirical investigation," Education and Information Technologies, 2019.

[7] M. Barak and A. Levenberg, "Flexible thinking in learning: An individual differences measure for learning in technology-enhanced environments," Computers \& Education ScienceDirect, vol. 99, pp. 39-52, 2016.

[8] S. Ouf, M. A. Ellatif, S. E. Salama and Y. Helmy, "A proposed paradigm for smart learning environment based on semantic web," Computers in Human Behavior, pp. 196$818,2017$.

[9] R. Koper, "Conditions for effective smart learning environments," Smart Learning Environments, vol. 1, no. 5, 2014.

[10] S. Katalnikova, L. Novickis, N. Prokofyeva and V. Uskov, "Intelligent Collaborative Educational Systems and Knowledge Representation," Procedia Computer Science, vol. 104, pp. 166-173, 2017.

[11] B. Vesin, K. Mangaroska and M. Giannakos, "Learning in smart environments: usercentered design and analytics of an adaptive learning system," Smart Learning Environments, vol. 5, no. 24, 2018.

[12] A. Finogeev, A. Kravets, M. Deev, A. Bershadsky and L. Gamidullaeva, "Life-cycle management of educational programs and resources in a smart learning environment," Smart Learning Environments, vol. 5, no. 9, 2018.

[13] Y. Gambo and M. Z. Shakir, "New Development and Evaluation Model for SelfRegulated Smart Learning Environment in Higher Education," in IEEE Global Engineering Education Conference (EDUCON), Dubai, 2019.

[14] J. Dron, "Smart learning environments, and not so smart learning environments: a systems view," Smart Learning Environments, vol. 5, no. 25, 2018.

[15] L. J. Thomas, M. Parsons and D. Whitcombe, "Assessment in Smart Learning Environments: Psychological factors affecting perceived learning," Computers in Human Behavior, vol. 95, pp. 197-207, 2018.

[16] B. Gros, "The design of smart educational environments," Smart Learning Environments, vol. 3, no. 15, 2016.

[17] M. N. Giannakos, D. G. Sampson and Ł. Kidziński, "Introduction to smart learning analytics: foundations and developments in video-based learning," Smart Learning Environments, vol. 3, no. 12, 2016.

[18] M. Sung, "A Study Of Adults' Perception And Needs For Smart Learning," Procedia Social and Behavioral Sciences, vol. 191, pp. 115-120, 2015. 
[19] T. S. H. Teo, S. L. Kim and L. Jiang, "E-Learning Implementation in South Korea: Integrating Effectiveness and Legitimacy Perspectives," Information Systems Frontiers, 2018 . 